\title{
Left main coronary artery compression due to dilatation of the main pulmonary artery in patients with pulmonary hypertension: treatment and long-term follow-up
}

\author{
Compresión del tronco de la arteria coronaria izquierda por la dilatación de la arteria \\ pulmonar principal en pacientes con hipertensión pulmonar: tratamiento y seguimiento a \\ largo plazo
}

Juan M. Farina*, Guillermina Sorasio, Víctor Darú, and Adrián J. Lescano

Department of Cardiology, Red de Clínicas de Santa Clara. Buenos Aires, Argentina

A 56-year-old female patient who had been diagnosed with idiopathic pulmonary hypertension 3 years before the consultation presented to the emergency department referring a 2-week history of dyspnea and angina in functional Class III. Signs of right heart failure were confirmed (lower limb edema, mild bilateral pleural effusion, and positive hepatojugular reflux) at admission, as well as an increased intensity of second cardiac sound, and a pulmonary focus ejection murmur. Baseline diagnostic workup included an electrocardiogram that showed right ventricular hypertrophy and complete right bundle branch block. Doppler echocardiogram revealed right chambers dilation with a mild depression in right ventricular systolic function and a moderate tricuspid regurgitation with a peak velocity of $4.52 \mathrm{~m} / \mathrm{s}$, the estimated pulmonary artery systolic pressure was $90 \mathrm{mmHg}$ (based on an $82 \mathrm{mmHg}$ gradient between right ventricle and atrium added to a right atrium pressure of $8 \mathrm{mmHg}$ determined by inferior vena cava diameter and collapse). In addition, this method allowed the suspicion of the main coronary artery extrinsic compression as the cause of angina due to a severe dilation of the main pulmonary artery $(55 \mathrm{~mm})$, and of its main branches, was found ${ }^{1}$. Because of this suspicion, a chest computed tomography (CT) angiography was performed; it confirmed the severe dilation of the pulmonary artery $(54 \mathrm{~mm}$ in this case by this method) and showed an abnormal trajectory of the left main coronary artery, with critical reduction of its lumen, decreased distance between it and the pulmonary artery, and a very narrow angle with the left sinus of Valsalva (Fig. 1A)2. After assuming extrinsic compression by the pulmonary artery, a coronary angiography was performed for initially diagnostic and potentially therapeutic purposes. It revealed a proximal severe obstruction of the left main coronary artery, with TIMI (thrombolysis in myocardial infarction) 2 flow, and an almost parallel path to the left sinus of Valsalva due to the dislocation generated by the compression (Fig. 1B). For a better definition of the lesion intravascular, ultrasound was used; it showed an absence of atheromatous plaques and confirmed the severe reduction of proximal left main coronary artery diameter and the extrinsic nature of the obstruction (Fig. 1C) . $^{3}$ A $4.5 \times 20 \mathrm{~mm}$ drug-eluting stent was placed in the left main coronary artery, without complications. The patient evolved favorably, and annual follow-up with chest CT angiography was carried out, with no evidence of complications 3 years after the stent placement.
Correspondence:

*Juan M. Farina

E-mail: juan.farina@gmail.com
Available online: 04-12-2020 Arch Cardiol Mex (Eng). 2020;90(3):325-328 www.archivoscardiologia.com
article under the CC BY-NC-ND s article under the CC BY-NC-ND 


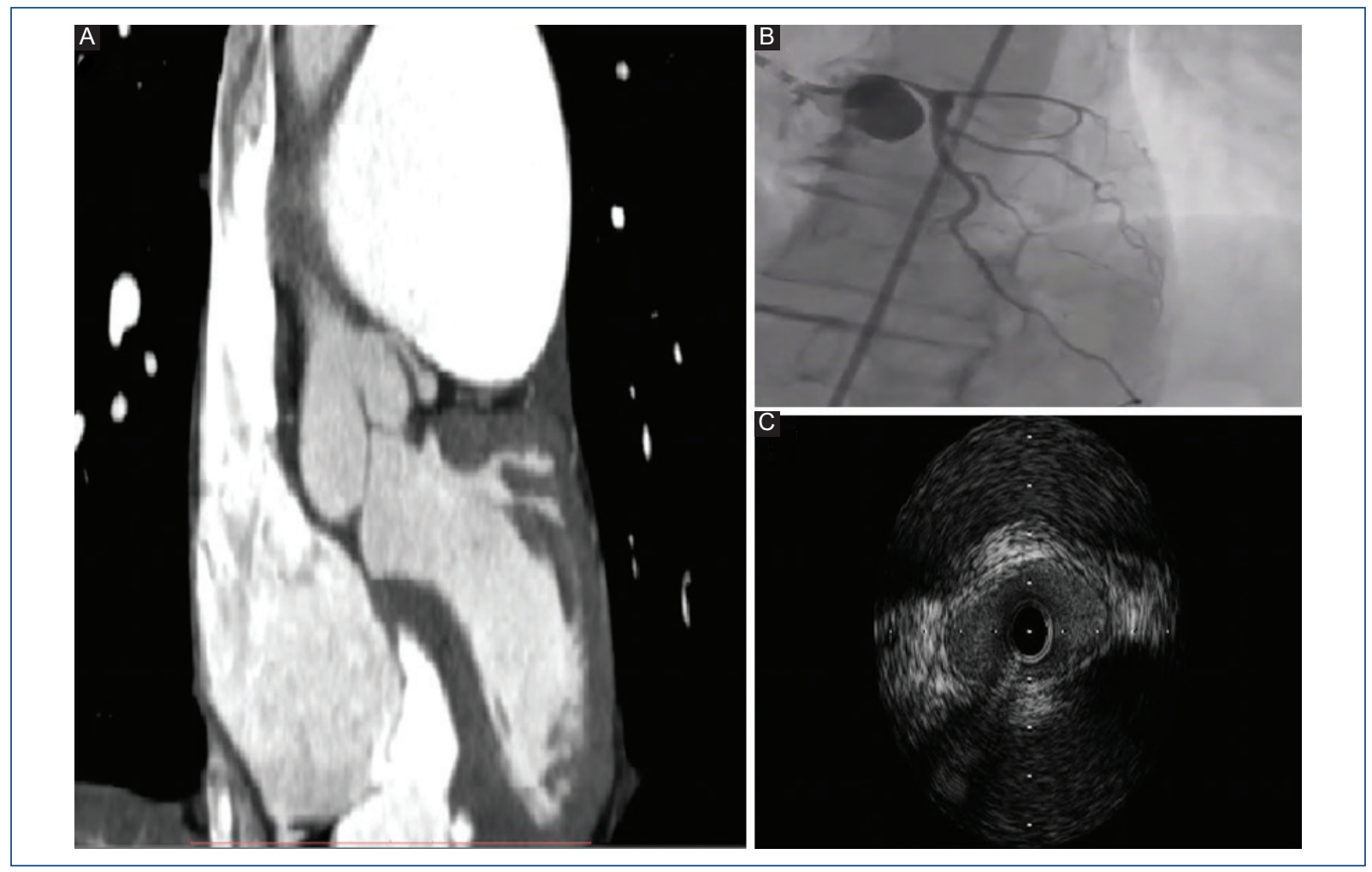

Figure 1. A: chest computed tomography angiography, coronal reconstruction: marked dilation of the pulmonary artery with narrow space between it and the sinus of Valsalva, which modifies the path of the left main coronary artery. Notice the extremely narrow angle between the sinus of Valsalva and the left main coronary artery, with reduction of ITS lumen. B: coronary angiography: severe narrowing of the left main coronary artery from its origin. The rest of the left coronary tree shows no significant lesions. C: intravascular ultrasound: the presence of atherosclerotic plaques is ruled out. Deformation of the left coronary artery lumen is observed, which initially becomes elliptical due to compression until becoming minimal $\left(2 \mathrm{~mm}^{2}\right)$.

In patients diagnosed with pulmonary hypertension, angina is a frequent symptom, which is referred by $35-40 \%$ of all patients with this condition ${ }^{4}$. Its occurrence has been generally attributed to a metabolic imbalance generated by the right ventricular hypertrophy and overload rather than to coronary involvement ${ }^{5}$. However, the left main coronary artery extrinsic compression due to dilation of the main pulmonary artery is an entity that is increasingly recognized as the cause of this symptom, with a reported prevalence close to $40 \%$ in patients with pulmonary hypertension who refer angina or anginous equivalents ${ }^{6}$. This mechanical complication is treatable, but in the absence of treatment, it can have serious consequences such as acute myocardial infarction, left ventricular dysfunction, cardiac arrhythmias, and even sudden death. In consequence, it is an entity with relevant clinical interest ${ }^{7}$. In regards to treatment, the possible alternatives are surgical procedures or percutaneous angioplasty. Considering the high surgical risk of pulmonary hypertension patients revascularization through percutaneous procedures with the placement of stents is currently preferred $^{8}$. There is no clear evidence about the type of stent that should be used (bare metal or drug-eluting stent), and the decision should, therefore, be made based on patient bleeding risk, with the use of bare metal stents in those with some predisposition to bleeding or who need anticoagulant treatment for another reason, to minimize the time on double anti-platelet aggregation treatment ${ }^{6}$.

There are few data on the long-term evolution and the complication rate of these procedures. In the reported case, in the absence of patient-referred symptoms during follow-up, a chest CT angiography was carried out every year, showing no evidence of restenosis or extrinsic compression 3 years after the procedure (Fig. 2). 


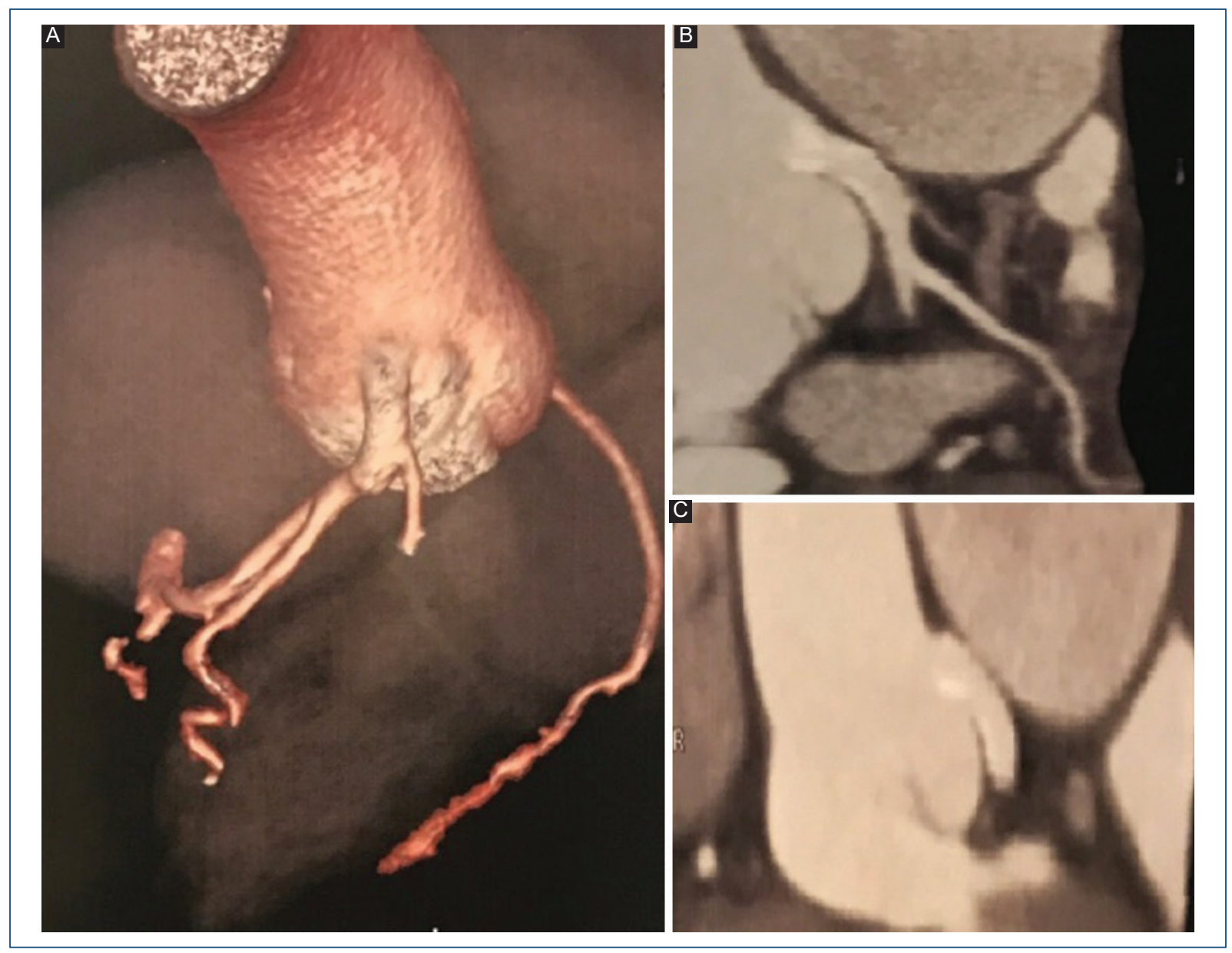

Figure 2. A: chest computed tomography (CT) angiography, three-dimensional reconstruction: caliber of the stent placed in the left main coronary artery is observed to be preserved, with no signs of restenosis or compression. B: chest CT angiography showing an absence of complications related to the implanted stent. C: abnormal path of the left main coronary due to dilation of the pulmonary artery.

\section{Conclusion}

The left main coronary artery extrinsic compression due to dilation of the pulmonary artery is an increasingly recognized cause of angina or other more severe complications in patients diagnosed with pulmonary hypertension. Its identification must be accurate through clinical suspicion and with the use of the appropiate diagnostic methods. First-line treatment is with percutaneous coronary interventions, considering the high surgical risk of these patients. Long-term follow-up, showing no complications 3 years after the procedure, aims to establish a contribution with regard to the longterm safety of this treatment.

\section{Conflicts of interest}

None.

\section{Funding}

The present investigation has not received any specific grant from public, commercial, or non-profit sector agencies.

\section{Ethical disclosures}

Protection of human and animal subjects. The authors declare that no experiments were performed on humans or animals for this research.

Confidentiality of data. The authors declare that they have followed the protocols of their work center on the publication of patient data.

Right to privacy and informed consent. The authors have obtained informed consent from the patients or subjects referred to in the article. This document is in the possession of the corresponding author. 


\section{References}

1. Lee S-E, An HY, Im JH, Sung JM, Cho I-J, Shim CY, et al. Screening of mechanical complications of dilated pulmonary artery related to the risk for sudden cardiac death in patients with pulmonary arterial hypertension by transthoracic echocardiography. J Am Soc Echocardiogr. 2016; 29(6):561-6.

2. Mesquita SMF, Castro CRP, Ikari NM, Oliveira SA, Lopes AA. Likelihood of left main coronary artery compression based on pulmonary trunk diameter in patients with pulmonary hypertension. Am $\mathrm{J}$ Med. 2004;15;116(6):369-74.

3. Seabra LF, Ribeiro HB, de Barros e Silva PGM, Rodrigues MJ, Spadaro AG, Conejo $F$, et al. Left main ostial compression in a patient with pulmonary hypertension: dynamic findings by IVUS. Am J Case Rep. 2015;16:899-903
4. Bhoil R, Sood S, Bhoil S, Chamail A, Sood RG. Extrinsic compression of left main coronary artery due to dilated pulmonary trunk resulting in ischaemic symptoms. Acute Card Care. 2016;18(1):23-4.

5. Alfonso $F$, Rivero $F$. Left main coronary artery compression in patients with pulmonary arterial hypertension. J Am Coll Cardiol. 2017; 69(23):2818-20.

6. Galiè N, Saia F, Palazzini M, Manes A, Russo V, Bacchi Reggiani ML, et al. Left main coronary artery compression in patients with pulmonary arterial hypertension and angina. J Am Coll Cardiol. 2017;69(23):2808-17.

7. Demerouti EA, Manginas AN, Athanassopoulos GD, Karatasakis GT. Complications leading to sudden cardiac death in pulmonary arterial hypertension. Respir Care. 2013;58(7):1246-54.

8. Caldera AE, Cruz-González I, Bezerra HG, Cury RC, Palacios IF, Cockrill BA, et al. Endovascular therapy for left main compression syn-drome. Case report and literature review. Chest. 2009;135(6):1648-50. 